INSTITUTE FOR DEFENSE ANALYSES

\title{
Evidence on the Effect of DoD Acquisition Policy and Process on Cost Growth of Major Defense Acquisition Programs
}

\author{
David L. McNicol \\ Linda Wu
}

September 2014

Approved for public release; distribution is unlimited.

IDA Paper P-5126

Log: H 14-000372

INSTITUTE FOR DEFENSE ANALYSES 4850 Mark Center Drive Alexandria, Virginia 22311-1882 
The Institute for Defense Analyses is a non-profit corporation that operates three federally funded research and development centers to provide objective analyses of national security issues, particularly those requiring scientific and technical expertise, and conduct related research on other national challenges.

About this Publication

This work was conducted by the Institute for Defense Analyses (IDA) under contract DASW01-04-C-0003, Project AY-7-357816, "Root Cause Analysis and Performance Assessment Methods and Analyses (Cost Growth 14)," for the Director, Performance Assessments and Root Cause Analyses (D,PARCA). The views, opinions, and findings should not be construed as representing the official position of either the Department of Defense or the sponsoring organization.

Acknowledgments

Thank you to Dr. Prashant Patel, Dr. Brian Rieksts, and Dr. David Sparrow for performing technical review of this document. We also are grateful to Dr. Sarah Burns for advice about and assistance with the statistical analysis.

\section{Copyright Notice}

(C) 2014 Institute for Defense Analyses

4850 Mark Center Drive, Alexandria, Virginia 22311-1882 • (703) 845-2000.

This material may be reproduced by or for the U.S. Government pursuant to the copyright license under the clause at DFARS 252.227-7013 (a)(16) [Sep 2011]. 
INSTITUTE FOR DEFENSE ANALYSES

IDA Paper P-5126

Evidence on the Effect of DoD Acquisition Policy and Process on Cost Growth of Major Defense Acquisition Programs

David L. McNicol

Linda Wu 



\section{Executive Summary}

This paper reports the results of research on whether changes in Department of Defense (DoD) acquisition policy and process have had a discernible effect on growth of Program Acquisition Unit Cost (PAUC) of major defense acquisition programs (MDAPs). The analysis is interesting primarily because it sheds some light on and - as it turns out - challenges important assumptions that often are implicit in discussions of acquisition reform.

\section{Acquisition Regime and PAUC Growth}

DoD acquisition policy and process over the period Fiscal Year (FY) 1970-FY 2007 can be grouped into five successive regimes:

1. The Defense Systems Acquisition Review Council (DSARC), 1970-1982

2. The Post-Carlucci Initiatives DSARC, 1983-1989

3. The Defense Acquisition Board (DAB), 1990-1993

4. Acquisition Reform (AR), 1994-2000

5. The DAB - Post Acquisition Reform, 2001-2007

The table on page iv displays the average PAUC growth for MDAPs that passed Milestone (MS) II/B or filed a first Selected Acquisition Report (SAR) in each of these regimes. The PAUC growth figures all are measured from the MS II/B baseline and normalized to the MS II/B total inventory objective. There are a number of interesting aspects to these data; for example, the high PAUC growth during the AR period and the lower PAUC growth for FY 2001-FY 2007. Granting that, the single most notable feature of these data is the absence of any trend in PAUC growth. If changes in acquisition policy and process have had a sustained influence on PAUC growth, it does not show up in this table. 
Average PAUC Growth in Successive Acquisition Regimes

\begin{tabular}{|c|c|c|c|}
\hline Acquisition Regime & Time Period & $\begin{array}{c}\text { Average PAUC } \\
\text { Growth }\end{array}$ & $\begin{array}{c}\text { No. of } \\
\text { Observations }\end{array}$ \\
\hline DSARC & 1970-1982 & $32 \%$ & 48 \\
\hline Post Carlucci Initiatives DSARC & $1983-1989$ & $19 \%$ & 40 \\
\hline DAB & 1990-1993 & $36 \%$ & 11 \\
\hline Acquisition Reform (AR) & $1994-2000$ & $66 \%$ & 27 \\
\hline DAB post $A R$ & $2001-2007$ & $19 \%$ & 25 \\
\hline
\end{tabular}

Broadly, there are two ways to explain the absence of sustained effects of acquisition policy and process on the PAUC growth data. First, they may in fact not have a strong or consistent effect on PAUC growth. Second, acquisition policy and process may have substantial effects that are masked by some other factor or factors.

\section{Funding Climate and PAUC Growth}

Thinking along the lines of the second of these possibilities led to consideration of whether changes in the DoD funding climate might be associated with PAUC growth. The period 1970-2007 includes two sub-periods during which acquisition funding was Relatively Constrained: FY 1970-FY 1980 and FY 1987-FY 2002. It also includes two sub-periods in which the acquisition funding climate was more accommodating: FY 1981-FY 1986 and FY 2003-FY 2007. The following table displays the average PAUC growth data for these four sub-periods.

Average PAUC Growth under Different DoD Topline Conditions

\begin{tabular}{|c|c|c|c|}
\hline \multicolumn{2}{|c|}{ Relatively Constrained } & \multicolumn{2}{|c|}{ Relatively Accommodating } \\
\hline Period (FY) & PAUC Growth & Period (FY) & PAUC Growth \\
\hline 1970-1980 & $35 \%(42)$ & 1981-1986 & $12 \%(35)$ \\
\hline 1987-2002 & $53 \%(55)$ & 2003-2007 & $7 \%(19)$ \\
\hline
\end{tabular}

Note: Numbers in parentheses are the number of observations available.

These data make it clear that MDAPs that passed MS II/B in Relatively Constrained funding climates had far larger PAUC growth than those that passed MS II/B in periods when the funding climate was Relatively Accommodating - by a factor of three in the first comparison and by a factor of five in the second.

\section{Acquisition Regime and Funding Climate}

The table on page $\mathrm{v}$ expands the table above by replacing the funding climate subperiods with the acquisition policy and process regimes. This table provides results for two sets of natural experiments. First, the PAUC growth columns give the effect of 
changes in the acquisition regime for a given funding climate. Second, the rows show the effect of funding climate for a given acquisition regime. For example, the first eleven years of the DSARC (FY 1970-FY 1980) were in a Relatively Constrained funding climate, while the next two (FY 1981-FY 1982) were in a period in which the climate for acquisition funding was Relatively Accommodating.

Average PAUC Growth by Acquisition Regime and Funding Climate

\begin{tabular}{lcc|ccc}
\hline & \multicolumn{2}{c|}{ Relatively Constrained } & \multicolumn{2}{c}{ Relatively Accommodating } \\
\cline { 2 - 3 } \multicolumn{1}{c}{ Acquisition Regime } & & Period (FY) & PAUC Growth & Period (FY) & PAUC Growth \\
\cline { 5 - 6 } \cline { 5 - 6 } DSARC & $1970-1980$ & $35 \%(42)$ & $1981-1982$ & $11 \%(6)$ \\
Post Carlucci DSARC & $1987-1989$ & $34 \%(11)$ & $1983-1986$ & $13 \%(29)$ \\
DAB & $1990-1993$ & $36 \%(11)$ & None & N/A \\
Acquisition Reform (AR) & $1994-2000$ & $66 \%(27)$ & None & N/A \\
DAB post AR & $2001-2002$ & $57 \%(6)$ & $2003-2007$ & $7 \%(19)$ \\
\hline
\end{tabular}

Note: Numbers in parentheses are the number of observations available.

Statistical analysis of the data behind the averages in this table leads to two conclusions. First, there is no statistically significant improvement or worsening of PAUC growth correlated with the different acquisition policy regimes. This is obvious for the Relatively Accommodating climate (column on the right). In contrast, PAUC growth over FY 1994-FY 2000 and in FY 2001-FY 2002 (column on the left) is noticeably higher than the averages for previous periods, but the differences proved not to be statistically significant because of the large variance among programs in each period.

Second, PAUC growth tends to be substantially higher in a Relatively Constrained funding climate than in the Relatively Accommodating climate. We have only three natural experiments of changes in funding climate for a given acquisition regime, since two of the five acquisition regimes (DAB and $A R$ ) fall entirely within one funding climate. Each of these three natural experiments on the effect of funding climate has the same outcome-MDAPs that passed MS II/B in a Relatively Constrained funding climate on average have a much higher PAUC growth rate than those that passed MS II/B in a Relatively Accommodating funding climate for a given acquisition regime. The outcomes of the first two experiments are virtually identical — an average PAUC growth of 35 and 34 percent, respectively, in the two periods when the topline was Relatively Constrained and average PAUC growth of 11 percent and 13 percent, respectively, in the two periods when the topline was Relatively Accommodating. The effect is most pronounced in the third experiment (DAB post-AR), which is statistically significant at the 1 percent confidence level, as are the differences for the DSARC and Post-Carlucci DSARC regimes. 


\section{Does the Resource Allocation Process Play a Major Role in PAUC Growth?}

These conclusions tend to challenge a fundamental assumption implicit in most discussions of acquisition reform: that the main, although not the only, causes of PAUC growth are to be found in the acquisition realm - the effectiveness of the Program Manager, the adequacy of the developmental test plan, the reasonableness of the cost estimate, the completeness of the systems engineering plan, among many others. This assumption is hard to maintain when the many changes in acquisition policy and process made in the past four decades have not had statistically significant effects on PAUC growth, but there is a statistically significant association between PAUC growth and funding climate.

The association between PAUC growth and funding climate suggests that the resource allocation process, particularly at the Service level, plays an important role in cost growth. This means more than "funding instability." Funding instability is a term of art for changes in MDAP funding through the annual resourcing cycle and "taxes." Funding instability is a chronic condition, present to some degree in all periods. What this paper observes is a recurring pattern - that MDAPs that passed MS II/B during periods when the DoD topline was Relatively Constrained, on average, had much higher PAUC growth than those that passed MS II/B during a period of Relatively Accommodating funding climate.

The conjecture that the resource allocation process plays an important role in cost growth gets some support from an unexpected direction-MDAPs with negative cost growth, of which there are twenty-nine in our sample. Negative PAUC growth is recorded if the actual cost of a program proves to be less than the cost in the MS II/B baseline. Assuming the program was funded to its MS II/B baseline, this implies that over time funds can be taken from the program in question and reallocated to other applications, including other acquisition programs. The program, then, effectively can be used as a "bank" - a way to hold reserves in relative safety until they are needed. A bank of this sort is more likely to be needed in a Relatively Accommodating funding climate, as it can then serve as a way to delay final decisions on the higher level of funding that has become available. We would therefore expect to find relatively more instances of negative PAUC growth in the Relatively Accommodating funding periods, and this is what we observe. About 30 percent of our observations in Relatively Accommodating funding climates are of negative PAUCs, compared to about 12 percent across the periods of Relatively Constrained climate.

MDAPs with "high cost growth," which we define as quantity normalized PAUC growth of at least 50 percent, also suggest an influence from resource considerations. DoD resource managers, particularly at the Service level, have only a few tools for responding to a Relatively Constrained funding climate. One of these is to impose top- 
down limits on the funding for particular MDAPs as they approach MS II/B. The result is likely to be particularly optimistic programmatic and costing assumptions, which leads to an expectation that relatively more high cost growth programs will be observed in periods of Relatively Constrained funding climate. This is what we observe. During periods of Relatively Constrained funding climate, about 40 percent of MDAPs had very high PAUC growth. In contrast, during periods of Relatively Accommodating funding climate only about 7 percent of MDAPs experienced high PAUC growth.

Taking both funding climates together, 85 percent of MDAPs with PAUC growth of at least 50 percent passed MS II/B during a Relatively Constrained funding climate. These MDAPs had an average PAUC growth of 93 percent and accounted for just over three-quarters of total PAUC growth. Excluding high cost growth MDAPs and MDAPs with negative PAUC growth, average PAUC growth across the two funding climates was just 18 percent. High PAUC growth is then predominantly a feature of programs with PAUC growth of at least 50 percent, and these programs mainly passed MS II/B in periods of Relatively Constrained funding climates. These points are important because they suggest that reforms directed to the average or typical MDAP may miss the real source of the problem.

\section{Implications for Discussions of Acquisition Reform}

This paper points to three implications for a discussion of acquisition reform. First, the relevant context for understanding PAUC growth is the interface between the acquisition process and the resource allocation process. The crucial evidence behind this point is the strong association between funding climate and PAUC growth. Resource managers must think in terms of a portfolio of programs across mission areas and commodity types, and extending from efforts in the technology base through programs nearing the end of production. When a program is completed, it opens a resource "hole" that programs emerging from Engineering and Manufacturing Development can occupy. In turn, programs earlier in the acquisition cycle can move forward as well. When funding for acquisition turns down, these holes get smaller, or close entirely, or require cuts in funding for ongoing programs. The alternatives available in this circumstance are all undesirable - cancellations of programs, delays in new starts, stretches, and adoption of unrealistic cost estimates. The evidence suggests that it is in this context that high PAUC growth arises.

Second, it seems unlikely that further broad changes in the acquisition process would have a major effect on PAUC growth. The research found no evidence that the efforts to strengthen the acquisition process through the years have resulted in lower or higher PAUC growth. This does not mean that the DAB process does not provide a useful discipline on acquisition programs; moreover, further changes in acquisition policy or process might be warranted for reasons of good government. The evidence does, at a 
minimum, suggest that the effects of changes in the acquisition process since its inauguration in the early 1970s have not had a dominant effect on PAUC growth.

Third, it is difficult to see that the cultures of the DoD acquisition organizations are a crucial obstacle to improved performance on cost growth. The key point to note is that high PAUC growth is not persistent, but rather episodic, and correlated with environmental factors outside of the control of the acquisition process. There is remarkably little PAUC growth in periods when the funding is Relatively Accommodating. It seems fair to ask if it makes sense to assert that an entrenched culture sometimes results in high cost growth and other times in low cost growth. Just how is it that the A team takes the field so quickly when the budgetary sun comes out? And why, even in bad budgetary weather, do more than half of MDAPs exhibit comparatively modest PAUC growth? 


\section{Contents}

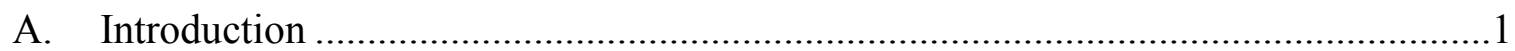

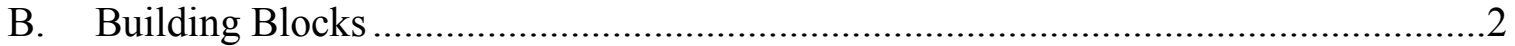

1. Acquisition Regimes .................................................................................. 3

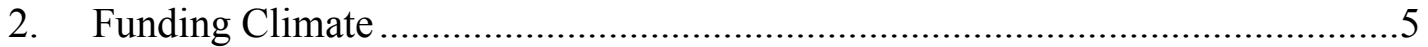

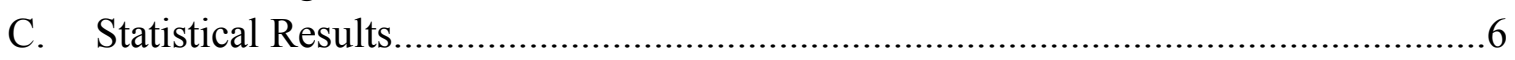

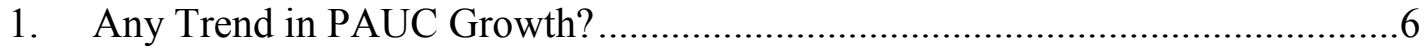

2. Association of Funding Climate and PAUC Growth ........................................

D. Is High PAUC Growth Systemic in the Relatively Constrained Funding Climate? ...9

E. Does the Resource Allocation Process Play a Major Role in PAUC Growth? .........11

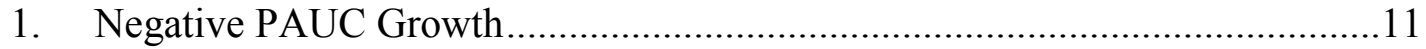

2. PAUC Growth $\geq 50$ Percent ....................................................................... 12

3. Reexamination of Trends in PAUC Growth ...............................................13

F. Implications for Discussions of Acquisition Reform ..........................................14

Appendix A. The Data ...................................................................................... A-1

Appendix B. Evidence on the Influence of the Funding Climate Prevailing at MS II/B on

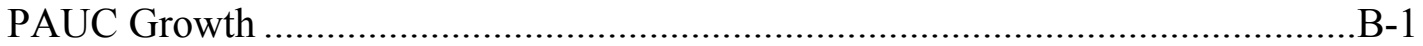

Appendix C. Average PAUC Growth by Acquisition Regime, Topline Condition, and Military Department/ Joint Program ..................................................................

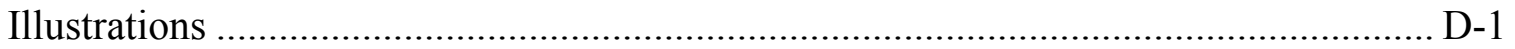

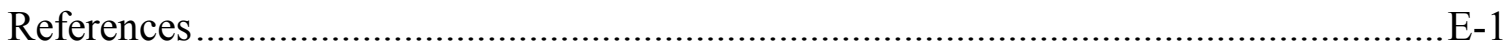

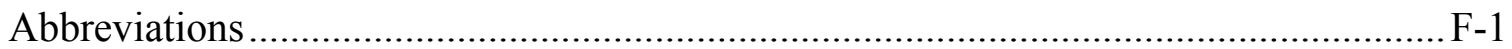

Supporting data files provided on CD (inside back cover):

McCrillis.pdf

Table A-1 Main Database_090814.xlsx

Table A-2 Memo Entries_090814.xlsx

Table A-4 CLC, DLC, and NQC PAUC Growth Estimates.xlsx 



\section{A. Introduction}

This paper reports the results of research on whether changes in Department of Defense (DoD) acquisition policy and process have had a discernible effect on growth of Program Acquisition Unit Cost (PAUC) of major defense acquisition programs (MDAPs). A few previous studies have broached this topic, but it has received little attention, and the work that has been done has not resulted in any accepted or even widely recognized conclusions. ${ }^{1}$

The establishment of the Defense Systems Acquisition Review Council (DSARC) in late Fiscal Year (FY) 1969 marks the start of systematic Office of the Secretary of Defense (OSD) oversight of MDAPs. While an initiative of then Deputy Secretary of Defense David Packard, the DSARC responded to intense congressional concerns with growth in the costs of major DoD weapon system acquisition programs. It appears to have generally been regarded at the time as a successful innovation.

There have been many changes, large and small, in DoD acquisition policy and process since the DSARC was established. Many of these were undertaken simply for reasons of good government - to reduce the costs of the decision-making process and the time it requires, to increase its transparency, to make it more responsive to policy direction, and to adapt it to changes in the technological and national security environment. Many others were aimed directly at improving outcomes on MDAPs - in particular, reducing cost growth. This study was undertaken in the hope that a better understanding of the effects of these changes in acquisition policy and process on PAUC growth will contribute to the long-running discussion of reform of the DoD acquisition process.

Finding or making estimates of PAUC growth for a sufficiently large set of MDAPs was the first major challenge faced by this study. We have a PAUC growth estimate for

1 The literature includes many analyses of particular acquisition policies. There also have been several largely qualitative studies of, for example, the extent to which a set of related initiatives has been successful or, to offer another example, the apparent successes and shortcomings of the acquisition process over a specific time period, such as a decade. In contrast, there have been few broad quantitative assessments of the effectiveness of acquisition policy and process. The main predecessors of this work, in particular, are David L. McNicol, Cost Growth in Major Weapon Procurement Programs, 2nd edition (Alexandria, VA: Institute for Defense Analyses, 2005), especially pages 41-44 and 55-59, and Tyson et al., "The Effects of Management Initiatives on the Costs and Schedules of Defense Acquisition Programs, Vol. I Main Report," IDA Paper P-2722 (Alexandria, VA: Institute for Defense Analyses, 1992). More recently, Obaid Younossi et al., in Is Weapon System Cost Growth Increasing? A Quantitative Assessment of Completed and Ongoing Programs (Santa Monica, CA: The RAND Corporation, 2007), concluded from their careful study of trends in development cost growth that "despite the many acquisition reform and other DoD management initiatives over the years, the development cost growth of military systems has not been reduced." (Summary page $\mathrm{xx}$ ) References to the previous literature are provided in both McNicol and Younossi. 
151 of the 309 distinct MDAPs that filed at least one SAR during FY 1969- FY 2007, a bit less than half of the total. The programs for which we have a PAUC growth estimate do not include any of the approximately seventy-five MDAPs that were terminated with little or no production. It would be interesting to have a reasonable PAUC growth estimate relative to the Milestone (MS) II/ $\mathrm{B}^{2}$ baseline for these programs, but developing such estimates would require far more resources than were available for this study. The study, then, does not provide a comprehensive picture of cost growth; doing so was not its intent. The question asked is whether changes in acquisition policy and process over time have visibly had an influence on PAUC growth. We ask that question for MDAPs that passed MS II/B as Acquisition Category (ACAT) I programs and progressed into full rate production. The question is not explored for programs that were cancelled or truncated.

Appendix A describes the sources of our PAUC growth estimates and puts the MDAPs for which we have a PAUC growth estimate in the context of the entire population of MDAPs. The data we used are included on a compact disc (CD) in a pocket on the inside back cover of this report. Unless stated otherwise, PAUC growth here means PAUC growth normalized to the MS II/B baseline quantity.

The second major challenge was one of research design. In broad outline, the paper identifies natural experiments that may shed some light on the effects of acquisition policy on PAUC growth and then interprets the outcomes of those experiments. In part, this is straightforward. We know when the main changes in acquisition policy and process occurred and what they were. The overall DoD acquisition funding climate in various periods - the second main element of the natural experiment - also can be readily established. The problem is that, in addition to the easily identified elements of the natural experimental design, there are a considerable number of other factors that had some influence on PAUC growth. We first limit attention to acquisition regime and funding climate and then, as particular results are stated, ask whether they are compromised by the omission of other factors.

\section{B. Building Blocks}

Discussions of acquisition reform over the past twenty-five years have usually put DoD Program Manager (PM) and personnel in the program office in the foreground. These people oversee the contractors and do a myriad of things that must be done by the government for a major acquisition program to move forward-contracting, financial management, and test planning, among many others. In the background are the

DoDI 5000.2 issued Oct. 23, 2000, formally established Milestones A, B, and C (in place of Milestones I, II, and III) as the main decision points for an MDAP. Milestones A, B, and C began to be used somewhat earlier for new programs, however. 
contractors who typically do the development and manufacturing. A good program will not occur if the government personnel and contractors do not do their jobs well. It is equally true that if these individuals and organizations do their jobs well, a good outcome for the program is more likely.

What this focus on the DoD PM, the program office personnel, and the contractors' PMs and workers leaves out are factors they must accept as "givens." These givens are subject to changes - sometimes large and fairly sudden - that presumably have substantial consequences for program outcomes. One of the givens is the topline DoD funding constraint, which does not determine, but generally has a marked influence on, the funding for individual MDAPs. A second is DoD acquisition policy and process. We begin with the latter.

\section{Acquisition Regimes}

This paper distinguishes five successive DoD acquisition regimes: ${ }^{3}$

1. The Defense Systems Acquisition Review Council (DSARC), 1970-1982

2. The Post-Carlucci Initiatives DSARC, 1983-1989

3. The Defense Acquisition Board (DAB), 1990-1993

4. Acquisition Reform (AR), 1994-2000

5. The DAB - Post Acquisition Reform, 2001-2007 (because our PAUC growth data ends in 2007)

The transition from the first phase of the DSARC (1970-1982) to the second was principally a matter of policy direction and renewal. The thirty-four Carlucci Initiatives (regime number 2) were intended to increase the efficiency and effectiveness of the OSD acquisition oversight process and the Planning, Programming, and Budgeting System (PPBS). While the DAB (number 3) itself bears a strong family resemblance to the DSARC, the statute creating it directed management changes intended to strengthen what is now the Under Secretary of Defense (Acquisition, Technology, and Logistics) (USD(AT\&L)). This statute also created the position of Vice Chairman of the Joint Chiefs of Staff (VCJCS) and directed a new requirements process centered on the

The main reference we have used is J. Ronald Fox, Defense Acquisition Reform, 1960 to 2009: An Elusive Goal (Washington, DC: U.S. Army Center of Military History, 2011). Fox identifies the main features of each of these periods as well as the most important changes that took place within them.

4 After then Deputy Secretary of Defense Frank Carlucci. There is some uncertainty about when the PostCarlucci Reforms DSARC should end and the DAB regime should begin. The relevant statutes were passed in 1986, and the DAB began functioning under that name in late FY 1987 or early FY 1988; however, DoD did not implement the full set of reforms required by statute until 1990. We have for that reason set the line at 1990 . 
VCJCS. The results sought by AR (number 4) were improvements in MDAP outcomes, but changes made during that period (not all part of AR) somewhat relaxed OSD oversight of MDAPs. There were, in particular, substantial cuts in acquisition staffs at both the OSD level and Service Headquarters level, and senior decision makers took a more permissive attitude towards cost growth. The Post-AR regime (number 5) was marked by the arrival of a new administration in January 2001, which brought policy changes but no major changes to the acquisition process or statutes.

Table 1 displays the average PAUC growth for MDAPs that passed MS II/B or filed a first SAR in each of these successive regimes. There are a number of interesting aspects to these data; for example, the high PAUC growth during the AR period and the lower PAUC growth for FY 2001-FY 2007. Granting that, the single most notable feature of these data is the absence of any trend in PAUC growth. If changes in acquisition policy and process have had a sustained influence on PAUC growth, it does not show up in this table.

Table 1. Average PAUC Growth in Successive Acquisition Regimes

\begin{tabular}{|c|c|c|c|}
\hline Acquisition Regime & Time Period & $\begin{array}{c}\text { Average PAUC } \\
\text { Growth }\end{array}$ & $\begin{array}{c}\text { No. of } \\
\text { Observations }\end{array}$ \\
\hline DSARC & 1970-1982 & $32 \%$ & 48 \\
\hline Post Carlucci Initiatives DSARC & 1983-1989 & $19 \%$ & 40 \\
\hline $\mathrm{DAB}$ & $1990-1993$ & $36 \%$ & 11 \\
\hline Acquisition Reform (AR) & 1994-2000 & $66 \%$ & 27 \\
\hline DAB post AR & $2001-2007$ & $19 \%$ & 25 \\
\hline
\end{tabular}

In constructing Table 1, we assigned the PAUC growth of each program to the acquisition regime in place when the program passed MS II/B or filed its first SAR. At first glance this may seem dubious, since a program can easily take ten or fifteen years from the start of Engineering and Manufacturing Development (EMD) through delivery of the final production lot and thus spend parts of its acquisition cycle under successive acquisition regimes. Note, however, that our estimates are of PAUC growth measured from the baseline established at MS II/B, which does not change over the course of a program's acquisition cycle. It remains possible that the actual acquisition costs of a program are significantly influenced by policy or process changes made after its MS II/B. Evidence presented in Appendix B suggests that if such influences exist, they are much smaller than the effect of the cost estimate in the MS II/B baseline.

Broadly, there are two ways to explain the absence of sustained effects of acquisition policy and process on the PAUC growth data. First, they may in fact not have a strong or consistent effect on PAUC growth. Second, acquisition policy and process may have substantial effects that are masked by some other factor or factors. 


\section{Funding Climate}

Thinking along the lines of the second of these possibilities led to consideration of whether changes in the DoD acquisition funding climate might be associated with PAUC growth. We have a PAUC growth estimate for 151 MDAPs that passed MS II/B or submitted a first SAR during FY 1969-FY 2007. This period includes two sub-periods during which acquisition funding was Relatively Constrained: FY 1970-FY 1980 and FY 1987-FY 2002. We also have two sub-periods in which the acquisition funding climate was Relatively Accommodating: FY 1981-FY 1986 and FY 2003-FY 2007. (We did not include any program not at least five years beyond MS II/B, and the 2012 SARs were the last available for this study. $)^{5}$

Table 2 displays the average PAUC growth data for these four sub-periods. The average PAUC growth in periods of Relatively Constrained acquisition funding is far larger than it is in periods of a Relatively Accommodating funding climate-by a factor of three in the first comparison and by a factor of five in the second.

Table 2. Average PAUC Growth during Different Acquisition Funding Climates

\begin{tabular}{|c|c|c|c|}
\hline \multicolumn{2}{|c|}{ DoD Topline Relatively Constrained } & \multicolumn{2}{|c|}{ DoD Funding Relatively Accommodating } \\
\hline Period (FY) & PAUC Growth & Period (FY) & PAUC Growth \\
\hline $1970-1980$ & $35 \%(42)$ & $1981-1986$ & $12 \%(35)$ \\
\hline $1987-2002$ & $53 \%(55)$ & 2003-2007 & $7 \%(19)$ \\
\hline
\end{tabular}

Note: Numbers in parentheses are the number of observations available.

What the data in Table 2 portray goes well beyond "budget instability" as usually understood. Budget instability is a term of art for changes in MDAP funding through the annual resourcing cycle and "taxes." Budget instability is a chronic condition, present to some degree in all periods. What this paper observed is a recurring pattern - that MDAPs that passed MS II/B during periods when the acquisition funding was Relatively Constrained, on average, had much higher PAUC growth than those that passed MS II/B during periods of a Relatively Accommodating funding climate.

5 We use as the breakpoints that define these periods events that marked major changes in expectations about the course of defense spending: (1) The invasion of Afghanistan by the Soviet Union in December 1979 (FY 1980), which about a month later led President Carter to announce a policy of sustained increases in defense spending starting with the FY 1981 funding; (2) the adoption in December 1985 (end of the first quarter of FY 1986) of the Gramm-Rudman-Hollings Act, the funding constraints of which effectively ended the Carter-Reagan defense buildup; and (3) the 9/11/2001attacks. It is important to recognize that key decisions made within DoD on content, costing, and funding for particular MDAPs in a given year are made at least a year in advance of the submission of the funding for that year to the Congress. Consequently, the DoD decisions in funding submissions reflect expectations about the climate that submission will encounter. 


\section{Statistical Results}

Table 3 expands Table 2 by replacing the funding climate sub-periods with the acquisition policy and process regimes. This table provides results for two sets of natural experiments. First, the PAUC growth columns give the effect of changes in the acquisition regime for a given funding climate. Second, the rows show the effect of funding climate for a given acquisition regime. For example, the first eleven years of the DSARC (FY 1970-FY 1980) were in a tight funding climate, while the next two (FY 1981-FY 1982) were in a period in which the acquisition funding climate was Relatively Accommodating.

The two sections that follow discuss, in turn, whether changes in acquisition policy and process have visible effects on PAUC growth, and the association between funding climates and PAUC growth.

Table 3. Average PAUC Growth by Acquisition Regime and Funding Climate

\begin{tabular}{lcc|cc}
\hline & \multicolumn{2}{c|}{ Relatively Constrained } & \multicolumn{2}{c}{ Relatively Accommodating } \\
\cline { 2 - 3 } \multicolumn{1}{c}{ Acquisition Regime } & Period (FY) & PAUC Growth & Period (FY) & PAUC Growth \\
\cline { 5 - 6 } DSARC & $1970-1980$ & $35 \%(42)$ & $1981-1982$ & $11 \%(6)$ \\
Post Carlucci DSARC & $1987-1989$ & $34 \%(11)$ & $1983-1986$ & $13 \%(29)$ \\
DAB & $1990-1993$ & $36 \%(11)$ & None & N/A \\
Acquisition Reform (AR) & $1994-2000$ & $66 \%(27)$ & None & N/A \\
DAB post AR & $2001-2002$ & $57 \%(6)$ & $2003-2007$ & $7 \%(19)$ \\
\hline
\end{tabular}

Note: Numbers in parentheses are the number of observations available.

\section{Any Trend in PAUC Growth?}

There is no doubt that direction from the Milestone Decision Authority (MDA) changes particular MDAPs, and some of those changes reduce the risks of major PAUC growth or other program performance shortfalls. Viewed from this perspective, the question asked here is whether the decisions made (or not made) in different acquisition regimes are large enough and frequent enough to be visible in average PAUC growth.

Looking first at the Relatively Accommodating climate (column on the right in Table 3) and recognizing that it is likely that the average PAUC growth for FY 2003FY 2007 eventually will be a few percentage points higher, ${ }^{6}$ we can see no trend towards

6 We have a PAUC growth estimate for nineteen of the twenty-five MDAPs that passed MS B as ACAT I programs during 2003-2007 and which have not been cancelled or truncated. Of these nineteen programs, six have been completed, six are in full rate production (FRP), three are in Low Rate Initial Production (LRIP), and four are in EMD. Younossi et al., in Is Weapon System Cost Growth Increasing?, found that on average, 60 percent of development cost growth occurs by five years after 
reduction in average PAUC growth in periods with a Relatively Accommodating funding climate. Statistical analysis is consistent with this impression; that is, we found no evidence of statistically significant differences among average PAUC growth rates for the Relatively Accommodating funding climate. ${ }^{7}$

The average PAUC growth rates for the two most recent acquisition regimes during a Relatively Constrained funding (column on the left in Table 3) are noticeably larger than those for the three earlier periods. Again, however, the statistical analysis did not indicate that any of the averages is statistically different from the others at the 1 percent confidence level.

Appendix C presents a table similar to Table 3 for each of the Military Departments and for joint programs. None shows an improving trend in PAUC growth in either of the two funding climates, and with a small number of exceptions, these tables show the same features we see in Table 3.

We have no fully comparable PAUC growth data for the periods before the DSARC was established. Consequently, the statistical analysis leaves open the possibility that the DSARC and its successors provided a useful discipline on acquisition programs. ${ }^{8}$ Moreover, the statistical analysis does not erase history. Weapon system cost growth was a particular concern during the 1980s - the sixth Carlucci Initiative was "Funding to Most Likely Costs"- and it is reasonable to believe that the Carlucci Initiatives did in fact lead to more vigorous enforcement of realistic funding. We also know that less emphasis was placed on weapon system cost growth during the AR years, and oversight of acquisition programs was somewhat more relaxed. It could be that these differences do provide part of the explanation for the higher observed average PAUC growth during the AR years. The statistical analysis prevents us from asserting with confidence that they do, however,

MS B. (31). Estimates of procurement cost growth also usually are increased as necessary to reflect EMD experience. Since each of the nineteen programs is at least five years beyond MS B, even a doubling of the 10 percent average PAUC growth would be unexpected.

7 The method used was one-way analysis of variance (ANOVA). ANOVA is a test of whether three or more samples are drawn from populations with the same mean. The null hypothesis is that all population means are equal; the alternative hypothesis is that at least one mean is different. In this case, the alternative hypothesis was rejected at the 1 percent level. ANOVA assumes that (1) the populations from which the samples were drawn are normally distributed, (2) the samples are independent, and (3) the variances of the populations are equal. We are grateful to Dr. Sarah Burns for her advice on the statistical analysis and for doing the computations.

8 The most nearly comparable data seems to be that in Table A-7 (pp. A-6 to A-8) of Appendix A of Tyson et al., "The Effects of Management Initiatives on the Costs and Schedules of Defense Acquisition Programs, Vol. I: Main Report." These data are quantity adjusted, but for some programs cost growth may not be measured from the estimates at the start of EMD, and the sample may include programs that were cancelled. Omitting one program with an extremely high cost growth (Condor), the average PAUC growth for the pre-1970 MDAPs was 48 percent, which is noticeably higher than the average PAUC growths during 1970-1978. 
because those differences are within the bounds of what can be expected from the variability of the data. ${ }^{9}$

It remains possible that factors that have not been considered in this paper mask significant influences of acquisition policy and process on PAUC growth that a more refined analysis would reveal. ${ }^{10}$ In considering this possibility, it must be kept in mind that the issue is growth in PAUC from the MS II/B baseline not the trend over time in costs for a commodity group or the acquisition portfolio as a whole. Such trends, which may well exist, do not necessarily imply more cost growth for individual programs, as they should be reflected in the MS II/B baselines. Further comments on possible confounding variables are made below. The conclusion offered here is that once we normalize for funding climate we do not observe any improvement in PAUC growth from the changes made over the years in acquisition policy and process.

\section{Association of Funding Climate and PAUC Growth}

Returning to Table 3 (on page 6) the relevant comparisons are between the Relatively Constrained and Relatively Accommodating funding climates for a given acquisition regime. Whereas the effects on PAUC growth of the different acquisition regimes are elusive, those of the contrasting funding periods stand out sharply.

We have only three experiments of changes in funding climate for a given acquisition regime, since two of the five acquisition regimes (DAB and AR) fall entirely within one funding climate-Relatively Constrained. Each of these three natural experiments on the effect of funding climate has the same outcome-passing MS II/B during a Relatively Constrained funding climate is on average associated with much higher PAUC growth compared to passing during a Relatively Accommodating funding climate for a given acquisition regime. The outcomes of the first two experiments are virtually identical — an average PAUC growth of 35 and 34 percent, respectively, in the two periods when the topline was Relatively Constrained and average PAUC growth of 11 percent and 13 percent, respectively, in the two periods when the topline was

9 For example, the exceptionally high average PAUC growth during the AR years (66 percent) can be attributed in part to changes in the program mix. During the AR years, four helicopter programs passed MS II/B, one more than average for a period of this length. Moving the helicopter program with the highest PAUC growth (H-1 Upgrades) from 1994-2000 to 1987-1989 reduces the average PAUC growth for the AR years from 66 percent to 61 percent, and increases the average for 1987-1989 from 34 percent to 48 percent.

10 Results of McNicol, Cost Growth in Major Weapon Procurement Programs, 2nd edition, point to one possibility — changes in programs that occur after they pass MS II/B. This work considered growth in quantity normalized unit procurement costs after excluding costs of unforced changes in program content (i.e., changes not required to overcome some problem "baked into" the program in the MS II/B baseline). McNicol found evidence that some changes in the acquisition process had had a statistically significant effect on this measure of cost growth. See, in particular, pp. 43-44 and 55-56. 
Relatively Accommodating. The effect seems most pronounced in the third experiment (DAB post-AR) - 57 percent for FY 2001-FY 2002 and 7 percent for FY 2003-FY 2007. (As noted earlier, PAUC growth for the later period will increase somewhat as the programs of that period are completed; see footnote 7 on page 7.) The statistical analysis found the each of these differences to be significant at more than the 1 percent level. ${ }^{11}$

There is a distinct pattern to the changes in funding climate over our sample period-bust, boom, bust, boom. If some other factor or combination of factors is actually at work, rather than funding climate, it would have to have this same pattern. One possibility is that the methods used to estimate PAUC growth for MDAPs that passed MS II during FY 1989-FY 2007 are not the same as the method used for those that passed MS II during FY 1970-FY 1988. The limited evidence we have on this possibility is presented and discussed in the section in Appendix A entitled "Comparison of the PA\&E and CLC PAUC Growth Estimates" (page A-7). It suggests that differences in estimating methods do not explain the low average PAUC growth recorded for FY 2003-FY 2007 or the comparatively high cost growth observed for FY 1990FY 2002. The obvious interpretation of Table 3, and the one we believe to be correct, is that it really is changes in funding climate at work.

This does not mean that a Relatively Constrained funding climate causes PAUC growth. The proximate causes of PAUC growth are decisions embedded in programs approved at MS II/B (unrealistic cost estimates or programmatic assumptions, for example) and decisions made during program execution (such as failing to act promptly enough on test results) that eventually lead to PAUC growth. The correlation observed between higher PAUC growth and periods of tighter funding climate observed does suggest that programs are more likely to be burdened with such decisions if they passed MS II/B during a Relatively Constrained funding climate.

\section{Is High PAUC Growth Systemic in the Relatively Constrained Funding Climate?}

Based on the analysis thus far, it would not be surprising to find that almost all programs that pass MS II/B during a period with a Relatively Constrained funding climate are burdened with the sorts of very optimistic programmatic and costing assumptions that tend to result in high PAUC growth. Alternatively, the bulk of the cost growth might be accounted for by a relatively small number of MDAPs. Which of these two cases is the more nearly accurate is relevant to discussion of acquisition reform. In the first case it is reasonable to assume that PAUC growth is a systemic problem. It is often said, for example, that the acquisition culture has a bias in favor of optimistic

11 In this case we used the usual one-tail test for the difference between the means of samples drawn from what are assumed to be normal populations. 
programmatic and cost assumptions. PAUC growth looks much less like a systemic problem with the acquisition process, however, if most of it is due to a small number of MDAPs.

The first column of Table 4 shows the average PAUC growth (in periods of Relatively Constrained funding climate) of MDAPs that had a PAUC growth between zero and 50 percent. The average for these MDAPs was a PAUC growth of about 22 percent. The second column shows the average PAUC growth of those MDAPs that experienced a PAUC growth of at least 50 percent. These range from a low of 71 percent (FY 1970-FY 1980) to a high of 122 percent (FY 1994-FY 2000). The average of these values is 94 percent. Finally, the last column in Table 4 shows the percentage of PAUC growth in these periods accounted for by MDAPs with PAUC growth of at least 50 percent. The range is 62 percent to 89 percent and, averaged across all five periods, the high cost growth MDAPs accounted for just over three-quarters of total PAUC growth. (The figures shown in Table 4 are computed from simple averages rather than weighted by program size. ${ }^{12}$ ) In short, PAUC growth is mainly an affliction of Relatively Constrained funding climates and it is primarily due to a minority of programs - on the order of 37 percent - that experience PAUC growth of upwards of 50 percent.

Table 4. Characteristics of PAUC Growth in Relatively Constrained Funding Climate

\begin{tabular}{|c|c|c|c|c|}
\hline Acquisition Regime & $\begin{array}{c}\text { Period } \\
\text { (FY) }\end{array}$ & $\begin{array}{c}\text { Average PAUC } \\
\text { Growth of } \\
\text { MDAPs with } \\
\text { PAUC Growth } \\
\text { between } \\
0 \% \text { and } 50 \% \\
\end{array}$ & $\begin{array}{l}\text { Average PAUC } \\
\text { Growth of } \\
\text { MDAPs with } \\
\text { PAUC Growth } \\
\geq 50 \%\end{array}$ & $\begin{array}{c}\% \text { of PAUC } \\
\text { Growth } \\
\text { Accounted for } \\
\text { by MDAPs with } \\
\text { PAUC Growth } \\
\geq 50 \%\end{array}$ \\
\hline DSARC & $1970-1980$ & $21 \%(22)$ & $71 \%(15)$ & $73 \%$ \\
\hline Post Carlucci DSARC & $1987-1989$ & $22 \%(7)$ & $117 \%(2)$ & $62 \%$ \\
\hline DAB & 1990-1993 & $21 \%(7)$ & $84 \%(3)$ & $64 \%$ \\
\hline Acquisition Reform & 1994-2000 & $22 \%(10)$ & $122 \%(13)$ & $89 \%$ \\
\hline DAB post AR & 2001-2002 & $29 \%(3)$ & $85 \%(3)$ & $75 \%$ \\
\hline
\end{tabular}

Note: Numbers in parentheses are the number of observations.

12 Weighting by program size would be required in any consideration of the effect of PAUC growth on funding, because cost growth on a large program has a greater effect on funding requirements than cost growth of the same magnitude on a smaller program. This paper, however, is concerned with examining the extent to which PAUC growth is associated with particular combinations of acquisition regimes and funding climates and in such a context, each observation counts as much as any other. 


\section{E. Does the Resource Allocation Process Play a Major Role in PAUC Growth?}

This section turns to a discussion of MDAPs that experienced very high cost growth (interpreted as a PAUC growth of at least 50 percent) and MDAPs that experienced negative cost growth. Investigation of this topic was initially prompted by the prospect that instances of high cost growth and perhaps also of negative cost growth mask effects of acquisition policy and process on PAUC growth. The topic proves to be interesting for other reasons as well. First, it provides clear and unexpected evidence of the connection between PAUC growth and funding climate and, by implication, the DoD resource allocation process. Second, cost growth proves not to be a problem with the typical system but with the minority of MDAPs that experience very high cost growth.

\section{Negative PAUC Growth}

Twenty-nine MDAPs in our sample show negative PAUC growth (not including four cases of zero PAUC growth). Viewed from an acquisition perspective, negative PAUC growth seems anomalous; in fact, it is not uncommon to hear confident assertions to the effect that MDAPs never underrun their funding. It is understandable, however, in a resource allocation context at the Service level.

Negative PAUC growth is recorded if the actual cost of a program proves to be less than the cost in the MS II/B baseline. Negative PAUC growth can occur because a program was particularly well managed or lucky. It also can occur if the ambitions of a program are scaled back after a program has passed MS II/B. In addition, negative PAUC growth can grow out of resource allocation imperatives.

Assuming the program was funded to its MS II/B baseline, negative PAUC growth implies that over time funds can be taken from the program in question and reallocated to other applications, including other acquisition programs. The program, then, effectively can be used as a "bank" - a way to hold reserves in relative safety until they are needed. A "withdrawal" can be made in the execution year with the approval of the Congress, but for the outyears of the Future Years Defense Plan (FYDP), the Service can simply initiate the reallocation in its Program/Funding submission to OSD.

A bank of this sort is more likely to be needed in a Relatively Accommodating funding climate, as it can then serve as a way to delay final decisions on allocation of the higher level of funding that has become available. We would therefore expect to find

relatively more instances of negative PAUC growth in the Relatively Accommodating funding periods, and this is what we observe. As the data in Table 5 indicate, about 30 percent of our observations in Relatively Accommodating funding climates are of negative PAUCs, compared to about 12 percent across the periods of Relatively Constrained climate. 
Table 5. Number of PAUC Growth Observations less than Zero by Acquisition Regime and Funding Climate

\begin{tabular}{|c|c|c|c|c|}
\hline \multirow[b]{2}{*}{ Acquisition Regime } & \multicolumn{2}{|c|}{$\begin{array}{c}\text { Topline Relatively } \\
\text { Constrained }\end{array}$} & \multicolumn{2}{|c|}{$\begin{array}{l}\text { Topline Relatively } \\
\text { Accommodating }\end{array}$} \\
\hline & $\begin{array}{l}\text { Time Period } \\
\text { (FY) }\end{array}$ & $\begin{array}{c}\text { PAUC Growth } \\
<0 \\
\end{array}$ & $\begin{array}{l}\text { Time Period } \\
\text { (FY) }\end{array}$ & $\begin{array}{c}\text { PAUC Growth } \\
<0\end{array}$ \\
\hline DSARC & 1970-1980 & 5 of 42 & 1981-1982 & 2 of 6 \\
\hline Post Carlucci DSARC & 1987-1989 & 2 of 11 & 1983-1986 & 10 of 29 \\
\hline $\mathrm{DAB}$ & 1990-1993 & 1 of 11 & None & N/A \\
\hline Acquisition Reform (AR) & 1994-2000 & 4 of 27 & None & N/A \\
\hline DAB post AR & 2001-2002 & 0 of 6 & $2003-2007$ & 5 of 19 \\
\hline
\end{tabular}

Negative PAUC growth is not regarded as a problem, probably correctly. It is, however, a clear and unexpected case in which PAUC growth reflects accommodation to the funding climate.

\section{PAUC Growth $\geq 50$ Percent}

Adoption of unrealistically low cost estimates at MS II/B creates the illusion that the funds available over the FYDP and beyond will support more MDAPs than they in fact will. That is, unrealistically optimistic costing will for a time permit more new starts. ${ }^{13}$ In addition, the conventional wisdom holds that a lower MS II/B cost makes it easier to gain the concurrence of OSD, the Office of Management and Budget, and the Congress for a new program. Consequently, we would expect to find relatively more programs with PAUC growth of at least 50 percent in Relatively Constrained funding climates, which is in fact what we do find.

Table 6 reports the number of programs with an average PAUC growth of at least 50 percent. Of the fifty-four programs that passed $\mathrm{MS}$ II/B in a Relatively Accommodating funding climate, only four showed PAUC growth of at least 50 percent. In contrast, thirty-six of the ninety-seven programs that passed MS II/B in a Relatively Constrained funding climate showed cost growth of at least 50 percent. This is to say that the frequency of MDAPs with a PAUC growth of at least 50 percent is much lower in periods when the topline is Relatively Accommodating than in a Relatively Constrained funding climate -7 percent versus 37 percent.

13 It is not clear that doing this ever makes financial sense because the "loans" created by unrealistically low cost estimates eventually must be made good one way or another at an implicit but steep interest rate. 
Table 6. Number of PAUC Growth Observations $\geq 50 \%$ by Acquisition Regime and Funding Climate

\begin{tabular}{|c|c|c|c|c|}
\hline \multirow[b]{2}{*}{ Acquisition Regime } & \multicolumn{2}{|c|}{$\begin{array}{c}\text { Topline Relatively } \\
\text { Constrained }\end{array}$} & \multicolumn{2}{|c|}{$\begin{array}{c}\text { Topline Relatively } \\
\text { Accommodating }\end{array}$} \\
\hline & $\begin{array}{l}\text { Time Period } \\
\text { (FY) } \\
\end{array}$ & $\begin{array}{c}\text { PAUC Growth } \\
\geq 50 \%\end{array}$ & $\begin{array}{c}\text { Time Period } \\
\text { (FY) }\end{array}$ & $\begin{array}{c}\text { PAUC Growth } \\
\geq 50 \%\end{array}$ \\
\hline DSARC & 1970-1980 & 15 of 42 & $1981-1982$ & 0 of 6 \\
\hline Post Carlucci DSARC & $1987-1989$ & 2 of 11 & $1983-1986$ & 3 of 29 \\
\hline DAB & $1990-1993$ & 3 of 11 & None & N/A \\
\hline Acquisition Reform (AR) & $1994-2000$ & 13 of 27 & None & $\mathrm{N} / \mathrm{A}$ \\
\hline DAB post $A R$ & $2001-2002$ & 3 of 6 & $2003-2007$ & 1 of 19 \\
\hline
\end{tabular}

\section{Reexamination of Trends in PAUC Growth}

The circumstances in which we are more likely to see very high PAUC growth and instances of negative PAUC growth suggest that they reflect accommodations to different funding climates. In other words, instances of high PAUC and negative PAUC may not reflect the normal operation of the acquisition process. On this basis, Table 7 presents average PAUC growths computed excluding observations of greater than or equal to 50 percent and negative values.

The statistical analysis of the data in Table 7 produces the same conclusions as that of Table 3 in one important respect: there is no indication of statistically significant differences across acquisition regimes within a funding climate. The difference between the averages in the two funding climates for the DAB post AR is, however, statistically significant at the 1 percent level, but the differences for the other two cases (DSARC and Post-Carlucci DSARC) are not statistically different at conventional levels of significance.

Table 7. Average PAUC Growth Excluding Observations $\geq 50$ Percent and Negative Observations by Acquisition Regime and Funding Climate

\begin{tabular}{|c|c|c|c|c|}
\hline \multirow[b]{2}{*}{ Acquisition Regime } & \multicolumn{2}{|c|}{$\begin{array}{l}\text { Topline Relatively } \\
\text { Constrained }\end{array}$} & \multicolumn{2}{|c|}{$\begin{array}{l}\text { Topline Relatively } \\
\text { Accommodating }\end{array}$} \\
\hline & $\begin{array}{c}\text { Time } \\
\text { Period (FY) } \\
\end{array}$ & $\begin{array}{l}\% \text { of PAUC } \\
\text { Growth }\end{array}$ & $\begin{array}{c}\text { Time } \\
\text { Period } \\
\text { (FY) }\end{array}$ & $\begin{array}{l}\% \text { of PAUC } \\
\text { Growth }\end{array}$ \\
\hline DSARC & $1970-1980$ & $21 \%(22)$ & $1981-1982$ & $22 \%(4)$ \\
\hline Post Carlucci DSARC & 1987-1989 & $22 \%(7)$ & $1983-1986$ & $13 \%(16)$ \\
\hline $\mathrm{DAB}$ & 1990-1993 & $21 \%(7)$ & None & N/A \\
\hline Acquisition Reform (AR) & 1994-2000 & $22 \%(10)$ & None & N/A \\
\hline DAB post AR & 2001-2002 & $29 \%(3)$ & 2003-2007 & $10 \%(13)$ \\
\hline
\end{tabular}

Note: Numbers in parentheses are the number of observations. 


\section{F. Implications for Discussions of Acquisition Reform}

This paper points to three implications for a discussion of acquisition reform. First, the relevant context for understanding PAUC growth is the interface between the acquisition process and the resource allocation process. The crucial evidence behind this point is the strong association between funding climate and PAUC growth. Resource managers must think in terms of a portfolio of programs across mission areas and commodity types, and extending from efforts in the technology base through programs nearing the end of production. When a program is completed, it opens a resource "hole" that programs emerging from EMD can occupy. In turn, programs earlier in the acquisition cycle can move forward as well. When funding for acquisition turns down, these holes get smaller, or close entirely, or require cuts in funding for ongoing programs. The alternatives available in this circumstance are all undesirable - cancellations of programs, delays in new starts, stretches, and unrealistic costing. The evidence summarized here suggests that it is in this context that high PAUC growth arises.

Second, it seems unlikely that further changes in the acquisition process would have a major effect on PAUC growth. The research found no evidence that acquisition policy and process changes through the years have produced sustained and significantly lower or higher PAUC growth. This does not mean that the DAB process does not provide a useful discipline on acquisition programs; moreover, further changes in acquisition policy or process might be warranted for reasons of good government. The evidence does, at a minimum, suggest that the effects of changes in the acquisition process since its inauguration in the early 1970s have not had a dominant effect on PAUC growth.

Third, it is difficult to see that the cultures of the DoD acquisition organizations are a crucial obstacle to improved performance on cost growth. The key point to note is that high PAUC growth is not persistent, but rather episodic, and correlated with environmental factors outside of the control of the acquisition process. There is remarkably little PAUC growth in periods when the funding is Relatively Accommodating. It seems fair to ask if it makes sense to assert that an entrenched culture sometimes results in high cost growth and other times in low cost growth. Just how is it that the A team takes the field so quickly and quietly when the budgetary sun comes out? And why even in bad budgetary weather do more than half of MDAPs exhibit comparatively modest PAUC growth? 


\section{Appendix A. \\ The Data}

All of the data used in this study were taken directly or indirectly from SARs. Broadly, two sorts of data are required. The first is MS II/B baseline data for each MDAP, especially the PAUC and the inventory objective, or total quantity to be acquired. Second, we need the same data from the final SAR filed by an MDAP, or for programs still underway, the Current Estimate (CE) from the December 2012 SAR. Our PAUC growth estimates reflect the actual PAUC (or the most recent $\mathrm{CE}$ ) normalized to the MS II/B quantity and divided by the MS II/B PAUC. They are, in short, as close as we can get to actual (quantity normalized) PAUC growth.

The first section of this appendix (The Population and the Sample) contains an overview of the sample of MDAPs for which we were able to obtain PAUC growth estimates and its relationship to the complete population of MDAPs. The second section of this appendix (PAUC Growth Estimates), beginning on page A-5, describes in detail the PAUC estimates used.

\section{The Population and the Sample}

The "stretch goal" of this paper was to identify all MDAPs that have ever filed a SAR and are at least five years into EMD, and to find a PAUC growth estimate relative to the MS II/B baseline for each of these programs. As is discussed in what follows, neither of these objectives was fully achieved.

\section{Memo Entries}

This research started with the list of programs that have filed at least one SAR implicit in the Defense Acquisition Management Information Retrieval System (DAMIRS) and a set of SARs available on an Office of the Under Secretary of Defense (Acquisition, Technology, and Logistics) (OUSD(AT\&L)) SIPRNet website. Together, these provide SARs under 345 distinct labels.

Not all of these were really distinct MDAPs, however:

- In several instances, each of the Services involved in a Joint program annually filed separate SARs, which, apart from some administrative information, were identical to each other.

- In some instances, separate MDAPs were merged into a single MDAP. 
- Conversely, there were instances in which a single MDAP was divided into two or more separate programs.

- The initial list included a number of instances in which a single MDAP appeared (usually in different years) under different names.

- A few of the items in the initial list are not MDAPs but Major Automated Information System (MAIS) programs.

- We found programs that filed a SAR after passing MS I but was cancelled before passing MS II. We also found a program (Patriot P3I) that filed only one SAR and was, in the next year, absorbed into the Patriot Advanced Capability-3 (PAC-3) program.

- Ballistic missile defense programs appear on the initial list under three different labels. In each case, the label covers a set of systems, not a single MDAP.

- The initial list included four chemical demilitarization programs. These are MDAPs, but the pressures on them and considerations that go into funding decisions on them mark them out as significantly different from major weapon system acquisition programs.

Most of these situations have a straightforward resolution. Duplicates, for example, clearly should not be in the main database, and whether the chemical demilitarization programs and the various incarnations of strategic missile defense are included is a matter of judgment. We excluded both and also excluded MAIS programs. Mergers and separations, in contrast, can be problematic. The guideline applied in these cases was as follows: Enter each program into the main database only once and, for mergers and separations, the default option is the program(s) that received MS II/B approval.

The thirty-six labels that appeared on the initial list of 345 and that were not included in the database were retained in a separate listing as "memo entries." The remaining 309 MDAPs are the population considered in this study. The CD provided with this paper (see the pocket on the inside back cover) provides both the main database (Table A-1) and the memo entries (Table A-2).

\section{Coverage}

We have an estimate of PAUC relative to MS II/B for 151 of the 309 MDAPs in our database - a bit less than half. Although accurate, this comparison leaves out an important point. Approximately seventy-five of the 309 MDAPs were cancelled (i.e., terminated before going into production) or truncated (i.e., terminated with little or no production beyond LRIP). Of the 228 MDAPs that eventually progressed into production, we have cost estimates for about two-thirds. 
It would be interesting to have a reasonable PAUC growth estimate relative to the MS II/B baseline for the programs that were cancelled or truncated, but developing such estimates would require far more resources than were available for this paper. ${ }^{1}$ The paper, then, does not provide a comprehensive picture of cost growth. Doing so was not its intent. The question asked was whether changes in acquisition policy and process over time have visibly had an influence on PAUC growth. We asked that question for MDAPs that passed MS II/B as ACAT I programs and progressed into full rate production. The question is not explored for programs that were cancelled or truncated or that passed MS II/B as ACAT II or ACAT III programs.

Table A-3 presents data on our coverage of Army, Navy/USMC, USAF, and Joint programs for FY 1969-FY 1974, FY 1975-FY 1988, FY 1989-FY 2001, and FY 2002FY 2007. Note that coverage is defined as the percentage of programs with a PAUC growth estimate divided by the number of programs that had significant production - that is, programs that were not cancelled or truncated.

For FY 1969-FY 1974 and FY 1975-FY 1988, programs were selected by the Office of Program Analysis and Evaluation (PA\&E) to provide a representative coverage of MDAPs. It appears that PA\&E was reasonably successful in doing so, although Joint programs are distinctly under-represented for FY 1969-FY 1974, and USAF programs are over-represented. The situation is much improved for FY 1975-FY 1988. The coverage ratios range from a low of about 63 percent for the Navy/USMC and a high of 92 percent for Joint programs.

The coverage ratios range from 59 percent to 94 percent for FY 1989-FY 2001 and 40 percent to 82 percent for FY 2002-FY 2007. The programs in these periods without PAUC growth estimates fall into two categories:

- Programs that passed MS II/B as ACAT II or ACAT III programs and later became ACAT I programs.

- Programs that passed MS II/B as ACAT I programs but were subsequently reorganized in a way that makes tracking the restructured program back to the MS II/B baseline difficult.

1 It is commonly assumed that there is a close association between PAUC growth and program cancellation or truncation. As a careful look at the data will show, high PAUC growth is neither a necessary nor a sufficient condition for an MDAP to be cancelled or terminated. Space-Based Infrared System (SBIRS)-High, for example, had an exceptionally high PAUC growth, but as of the December 2012 SAR, its planned acquisition quantity remained at 80 percent of the Milestone II baseline. In contrast, the Joint Standoff Weapon (JSOW) PAUC normalized to the MS II quantity decreased by 14 percent, yet (again as of the December 2012 SAR) the planned acquisition quantity was only 38 percent of the MS II baseline. 
The second of these problems could be overcome at least in some cases with sufficient effort, but the first probably cannot, because the data required cannot readily be obtained and, in fact, may no longer exist.

Table A-3. PAUC Growth Estimates as a Percentage of the Number of MDAPs for Which a PAUC Growth Estimate Could Be Made

\begin{tabular}{|c|c|c|c|c|c|}
\hline & & $\begin{array}{l}\text { FY 1969- } \\
\text { FY } 1974\end{array}$ & $\begin{array}{l}\text { FY 1975- } \\
\text { FY } 1988\end{array}$ & $\begin{array}{l}\text { FY 1989- } \\
\text { FY } 2001\end{array}$ & $\begin{array}{l}\text { FY 2002- } \\
\text { FY } 2007\end{array}$ \\
\hline \multirow[t]{5}{*}{ Army } & MDAPs & 15 & 30 & 23 & 8 \\
\hline & $\begin{array}{l}\text { Cancellations and } \\
\text { truncations }\end{array}$ & 4 & 7 & 7 & 3 \\
\hline & $\begin{array}{l}\text { Net: PAUC growth } \\
\text { estimate feasible }\end{array}$ & 11 & 23 & 16 & 5 \\
\hline & $\begin{array}{l}\text { Number of MDAPs with } \\
\text { PAUC growth estimate }\end{array}$ & 4 & 18 & 15 & 2 \\
\hline & Coverage & $36 \%$ & $78 \%$ & $94 \%$ & $40 \%$ \\
\hline \multirow[t]{5}{*}{ USN/USMC } & MDAPs & 23 & 45 & 25 & 14 \\
\hline & $\begin{array}{l}\text { Cancellations and } \\
\text { truncations }\end{array}$ & 1 & 10 & 3 & 3 \\
\hline & $\begin{array}{l}\text { Net: PAUC growth } \\
\text { estimate feasible }\end{array}$ & 22 & 35 & 22 & 11 \\
\hline & $\begin{array}{l}\text { Number of MDAPs with } \\
\text { PAUC growth estimate }\end{array}$ & 6 & 22 & 13 & 9 \\
\hline & Coverage & $27 \%$ & $63 \%$ & $59 \%$ & $82 \%$ \\
\hline \multirow[t]{5}{*}{ USAF } & MDAPs & 16 & 31 & 20 & 10 \\
\hline & $\begin{array}{l}\text { Cancellations and } \\
\text { truncations }\end{array}$ & 1 & 9 & 5 & 3 \\
\hline & $\begin{array}{l}\text { Net: PAUC growth } \\
\text { estimate feasible }\end{array}$ & 15 & 22 & 15 & 7 \\
\hline & $\begin{array}{l}\text { Number of MDAPs with } \\
\text { PAUC growth estimate }\end{array}$ & 6 & 15 & 12 & 5 \\
\hline & Coverage & $40 \%$ & $68 \%$ & $80 \%$ & $71 \%$ \\
\hline \multirow[t]{5}{*}{ Joint } & MDAPs & 6 & 17 & 12 & 12 \\
\hline & $\begin{array}{l}\text { Cancellations and } \\
\text { truncations }\end{array}$ & 2 & 5 & 4 & 5 \\
\hline & $\begin{array}{l}\text { Net: PAUC growth } \\
\text { estimate feasible }\end{array}$ & 4 & 12 & 8 & 7 \\
\hline & $\begin{array}{l}\text { Number of MDAPs with } \\
\text { PAUC growth estimate }\end{array}$ & 1 & 11 & 7 & 5 \\
\hline & Coverage & $25 \%$ & $92 \%$ & $88 \%$ & $71 \%$ \\
\hline
\end{tabular}




\section{PAUC Growth Estimates}

As was noted above, this study obtained or made estimates of PAUC growth for 151 MDAPs that passed MS II/B as ACAT I programs during the years FY 1969-FY 2007. These different sources and methods are described in what follows.

\section{PA\&E Cost Growth Database (PA\&E)}

PA\&E, now the Office of Cost Analysis and Program Evaluation, developed a database of cost growth experienced by MDAPs. This database is documented in a briefing by John McCrillis given at the 2003 Annual DoD Cost Analysis Symposium. ${ }^{2}$ (The $\mathrm{CD}$ included with this paper includes this briefing.)

The earliest cost estimates in the PA\&E database are from MDAPs that passed MS II in 1970, and the latest are for programs that passed MS B in FY 2001. The MDAPs in the PA\&E database were last updated using the December 2004 SARs. The PA\&E cost growth database included PAUC growth estimates for 93 MDAPs that were completed (that is, filed their last SAR) in FY 2004 or earlier. The other PAUC growth estimates in the PA\&E database had to be updated - which we did not have the data or resources to do - or replaced with a PAUC growth estimate made in some more summary fashion.

\section{No Quantity Change (NQC)}

The CE quantity was within \pm 1 percent of the MS II/B quantity for thirteen of the MDAPs from FY 1989-FY 2007. No quantity normalization is needed for these programs; their PAUC growth is computed by dividing the CE PAUC in the final SAR (or the December 2012 SAR for an ongoing program) by the MS II/B PAUC and subtracting 1. The PAUC growth for SBIRS-High $(\mathrm{H})$ also falls under this heading. The total number of SBIRS-H satellites to be acquired decreased from five (at MS II) to four (the December 2012 SAR). The decrease, however, was in a satellite purchased with Research, Development, Test and Evaluation (RDT\&E) funds, and we did not put these on a learning curve. There was no change in the number of SBIRS-H satellites purchased with procurement funds. Finally, although the PAC-3 quantity change fell outside the \pm 1 percent boundary, data limitations made it necessary to compute the PAC-3 PAUC growth as the ratio of the CE and MS II PAUCs. The relevant data for the NQC computations are included on the NQC worksheet in Table A-4 on the CD. The letters in the computation box at the top of the worksheet refer to the column headings for the data.

2 Accessible at https://dodcas.deltaresources.com/DODCAS\%20Archives /36th\%20DODCAS\%20\%282003\%29/Theme\%20-\%20Evolutionary\%20Acquisition/McCrillis.pdf. 


\section{DAMIRS Learning Curves (DLC)}

The DoD contractor staff for DAMIRS provided us with their estimates of learning curve parameters that we were able to use to compute PAUC growth for fourteen MDAPs that passed MS II/B during FY 1989-FY 2001. We refer to these as the DAMIRS Learning Curve (DLC) PAUC growth estimates. For each of these, we took the CE PAUC growth in program base-year dollars from the last SAR for the program or the December 2012 SAR (for still ongoing programs). The task was to normalize this PAUC estimate to the MS II/B quantity, which was done as follows:

- We used the learning curve to compute the recurring flyaway cost at the MS II/B baseline quantity.

- The CE estimates of RDT\&E and non-recurring flyaway cost were taken from the final SAR for the program or from the December 2012 SAR (for still ongoing programs).

- Support costs paid for with procurement dollars are, for many programs, primarily initial spares and support equipment, although other items may also fall into this category. Initial spares and support equipment normally scale with the number of units of the system purchased. For that reason, we used CE support cost reported in the last or most recent SAR scaled to the MS II/B baseline quantity.

The computations and the data used are laid out on the DLC worksheet in Table A-4 on the $\mathrm{CD}$ provided with this paper. The letters in the computation box at the top of the worksheet refer to the column headings for the data.

\section{Calibrated Learning Curve (CLC)}

There were twenty-nine MDAPs for which we did not have a PA\&E estimate and did not have estimated learning curve parameters, and for which the CE quantity was significantly different from the MS II/B quantity. The approach we used in those cases rested on a cost progress curve of the conventional form:

$$
C=T Q^{\beta}
$$

In this expression, $\mathrm{C}$ is recurring flyaway cost, $\mathrm{T}$ is first unit cost, $\mathrm{Q}$ is cumulative production, and $\beta$ is the cost progress parameter. We solved this and used the $\mathrm{CE}$ for recurring flyaway to get:

$$
\widehat{T}=C Q^{-\beta}
$$

A value of $\beta=0.94$ was used for each of the programs. This will be referred to as the

calibrated learning curve (CLC) method. From this point, the computations were the 
same as those for MDAPs for which DAMIRS staff provided the learning curve parameters.

The CLC worksheet in Table A-4 on the CD provides the data used in making the computations and indicates the details of the computations. The letters in the computation box at the top of the worksheet refer to the column headings for the data.

\section{Summary}

Table A-5 below provides a summary of the sources of the PAUC growth estimates for three different periods (which were marked off only for convenience in assembling the data). Table A-1 on the CD identifies the source of each estimate.

Table A-5. Sources of the PAUC Growth Estimates Used in Different Periods

\begin{tabular}{|c|c|c|c|c|c|}
\hline Period (FY) & PA\&E & NQC* & DLC & CLC & Total \\
\hline 1970-1988 & 83 & 0 & 0 & 0 & 83 \\
\hline 1989-2001 & 10 & 6 & 14 & 17 & 47 \\
\hline 2002-2007 & 0 & 8 & 0 & 13 & 21 \\
\hline Total & 93 & 14 & 14 & 30 & 151 \\
\hline
\end{tabular}

* No Quantity Change (i.e., CE quantity with \pm 1 percent of the MS II/B quantity.)

\section{Comparison of the PA\&E and CLC PAUC Growth Estimates}

The data in Table A-5 suggest the question of whether the results are influenced significantly by the different ways in which PAUC estimates are made. This is primarily a question about FY 2002-FY 2007, which has a notably low average PAUC growth (10 percent) and for which about two-thirds of the PAUC growth estimates were made with the CLC method. It is secondarily a question about FY 1989-FY 2001 in relation to FY 1970-FY 1988. In the earlier period, all of the PAUC growth estimates were from PA\&E, while in the later, about two-thirds were made using either the DLC or the CLC method.

The obvious approach to this issue is to compare the PA\&E PAUC growth for systems that have been completed with PAUC growth for those same systems computed using the DLC and the CLC methods. Unfortunately, there are no MDAPs that have been completed and for which we have both a PA\&E PAUC growth estimate and the data needed to compute a DLC or an CLC estimate.

The best we can do is to examine the twenty-three MDAPs that passed MS II/B during FY 1989-FY 2001 and for which we have a PA\&E PAUC growth estimate, a DLC estimate, and a CLC estimate. As was noted above, the PA\&E estimates were most recently updated with the 2004 SARs. The DLC and CLC estimates, in contrast, incorporated more recent data-either the final SAR for the program or, for ongoing 
programs, the December 2012 SAR. Consequently, in most cases we would expect the DLC and CLC PAUC growth estimates to be larger than the corresponding PA\&E estimate. That is the test: A method fails if it yields estimates that are "too often" and by "too much" less than the PA\&E estimates. Clearly, this is a weak test.

The relevant estimates are presented in Table A-6 on page A-9. The comparison of the PA\&E estimates and CLC estimates is on the left, and the comparison of the PA\&E and DLC estimates is on the right. The CLC estimates are larger than the PA\&E estimates for seventeen of the twenty-three MDAPs - in most cases, considerably larger. They are smaller in six cases (shaded rows). In all but one of these cases (Joint Direct Attack Munition, or JDAM) the differences are absolutely or relatively small. The average of CLC PAUC growth estimates is 77 percent in comparison to an average of 60 percent for the PA\&E estimates. The DLC estimates exhibit the same pattern. The average of the DLC estimates is 73 percent, and four of them (shaded rows) are less than the PA\&E estimate for the program, three by a substantial amount. 
Table A-6. Comparison of PA\&E, CLC, and DLC PAUC Growth Estimates for 23 MDAPs

\begin{tabular}{|c|c|c|c|c|c|}
\hline Program & PA\&E & CLC & Program & PA\&E & DLC \\
\hline LONGBOW APACHE & $78 \%$ & $117 \%$ & LONGBOW APACHE & $78 \%$ & $133 \%$ \\
\hline $\mathrm{F}-22$ & $41 \%$ & $71 \%$ & $\mathrm{~F}-22$ & $41 \%$ & $55 \%$ \\
\hline $\mathrm{F} / \mathrm{A}-18 \mathrm{E} / \mathrm{F}$ & $6 \%$ & $12 \%$ & $\mathrm{~F} / \mathrm{A}-18 \mathrm{E} / \mathrm{F}$ & $6 \%$ & $9 \%$ \\
\hline BRADLEY UPGRADE & $39 \%$ & $54 \%$ & BRADLEY UPGRADE & $39 \%$ & $86 \%$ \\
\hline MIDS & $30 \%$ & $72 \%$ & MIDS & $30 \%$ & $68 \%$ \\
\hline CEC & $48 \%$ & $62 \%$ & CEC & $48 \%$ & $62 \%$ \\
\hline H-1 UPGRADES & $124 \%$ & $192 \%$ & H-1 UPGRADES & $124 \%$ & $197 \%$ \\
\hline LPD 17 & $43 \%$ & $71 \%$ & LPD 17 & $43 \%$ & $72 \%$ \\
\hline $\mathrm{CH}-47 \mathrm{~F}$ & $147 \%$ & $173 \%$ & $\mathrm{CH}-47 \mathrm{~F}$ & $147 \%$ & $156 \%$ \\
\hline GMLRS/GMLRS AW & $125 \%$ & $249 \%$ & GMLRS/GMLRS AW & $125 \%$ & $243 \%$ \\
\hline MH-60S & $62 \%$ & $69 \%$ & MH-60S & $62 \%$ & $70 \%$ \\
\hline Tactical Tomahawk & $24 \%$ & $28 \%$ & Tactical Tomahawk & $24 \%$ & $27 \%$ \\
\hline GBS & $10 \%$ & $31 \%$ & GBS & $10 \%$ & $33 \%$ \\
\hline Stryker & $21 \%$ & $25 \%$ & Stryker & $21 \%$ & $22 \%$ \\
\hline UH-60M Black Hawk & $49 \%$ & $62 \%$ & UH-60M Black Hawk & $49 \%$ & $61 \%$ \\
\hline WGS & $28 \%$ & $55 \%$ & WGS & $28 \%$ & $42 \%$ \\
\hline C-130J & $70 \%$ & $84 \%$ & C-130J & $70 \%$ & $70 \%$ \\
\hline JPATS & $43 \%$ & $40 \%$ & JPATS & $43 \%$ & $44 \%$ \\
\hline SSN 774 & $35 \%$ & $33 \%$ & SSN 774 & $35 \%$ & $37 \%$ \\
\hline JDAM & $18 \%$ & $-10 \%$ & JDAM & $18 \%$ & $-13 \%$ \\
\hline JAVELIN & $229 \%$ & $197 \%$ & JAVELIN & $229 \%$ & $134 \%$ \\
\hline MH-60R & $95 \%$ & $74 \%$ & $\mathrm{MH}-60 \mathrm{R}$ & $95 \%$ & $80 \%$ \\
\hline NAS & $25 \%$ & $21 \%$ & NAS & $25 \%$ & $1 \%$ \\
\hline Average & $60 \%$ & $77 \%$ & & $60 \%$ & $73 \%$ \\
\hline
\end{tabular}

Note: The PA\&E estimates were updated only through the 2004 SARs. The CLC and DLC estimates incorporate information from the last SAR for the program or the December 2012 SAR (for still ongoing programs). 



\section{Appendix B. \\ Evidence on the Influence of the Funding Climate Prevailing at MS II/B on PAUC Growth}

As was noted in the main body of this paper (page 4), the PAUC growth of each program is assigned to the acquisition regime/funding climate in place when the program passed MS II/B or filed its first SAR. The extent to which this is reasonable is not immediately clear. On the one hand, a program can easily take ten or fifteen years from the start of EMD through delivery of the final production lot and thus spend part of its acquisition cycle under successive acquisition regimes. On the other hand, our estimates are of PAUC growth measured from the baseline established at MS II/B. This does not change over the course of a program's acquisition cycle, and to the extent that the main causes of cost growth are "baked into" the MS II/B baseline, we would not expect subsequent changes in funding climate or acquisition regime to have a major effect on PAUC growth.

This appendix presents evidence that bears on whether the actual acquisition costs of a program are significantly influenced by policy or process changes made after its MS II/B.

Case 1 in Table B-1 compares the FY 1970-FY 1972 cohort with that of FY 1978FY 1980. A program that passed MS II in 1970 was eleven years away from the next boom period of defense spending, which began in FY 1981. In contrast, a program that passed MS II in 1980 was born at the boundary of a period of growing funding; most of these programs would be expected to have completed EMD and entered LRIP before the Carter-Reagan defense boom ended with the FY 1986 budget. We might then expect the FY 1978-FY 1980 cohort to have a lower average PAUC growth associated with a Relatively Accommodating funding climate. In fact, we find the opposite. Similarly, in Case 2, we see the average PAUC growth for the FY 2000-FY 2002 cohort is the same as that for the FY 1987-FY 1989 cohort, even though starting in FY 2003, DoD entered a Relatively Accommodating funding climate. In Case 3 we find average PAUC growth higher for FY 1984-FY 1986 than for FY 1981-FY 1982 but still at a low value characteristic of periods of a Relatively Accommodating funding climate. The data then favor the position that the PAUC growth of programs tends to be characteristic of those of the periods in which they enter EMD and a complete Acquisition Program Baseline for the program is first established. 
Table B-1. Comparison of First Three and Last Three Years of Three Funding Climates in Terms of Average PAUC Growth and Instances of PAUC Growth of at Least $50 \%$

Case 1: Next Period of Relatively Accommodating Topline FY1979-FY1986

\begin{tabular}{|c|c|c|c|}
\hline Passed MS II during & $\begin{array}{c}\text { Average PAUC } \\
\text { Growth }\end{array}$ & PAUC Growth $\geq 50 \%$ & No. of Observations \\
\hline 1970-1972 & $18 \%$ & 2 & 9 \\
\hline 1978-1980 & $24 \%$ & 2 & 9 \\
\hline
\end{tabular}

Case 2: Next Period of Relatively Accommodating Topline FY2002-FY2007

\begin{tabular}{|c|c|c|c|}
\hline Passed MS II during & $\begin{array}{c}\text { Average PAUC } \\
\text { Growth }\end{array}$ & PAUC Growth $\geq 50 \%$ & No. of Observations \\
\hline 1987-1989 & $34 \%$ & 2 & 11 \\
\hline 2000-2002 & $45 \%$ & 3 & 8 \\
\hline
\end{tabular}

Case 3: Next Period of Relatively Constrained Topline FY1987-FY2001

\begin{tabular}{|c|c|c|c|}
\hline Passed MS II during & $\begin{array}{c}\text { Average PAUC } \\
\text { Growth }\end{array}$ & PAUC Growth $\geq 50 \%$ & No. of Observations \\
\hline 1981-1983 & $4 \%$ & 0 & 19 \\
\hline 1984-1986 & $22 \%$ & 3 & 16 \\
\hline
\end{tabular}




\section{Appendix C. \\ Average PAUC Growth by Acquisition Regime, Topline Condition, and Military Department/ Joint Program}

Table C-1. MDAPs Average PAUC Growth by Service, Acquisition Regime, and Topline Condition

\begin{tabular}{|c|c|c|c|c|}
\hline \multirow{2}{*}{$\begin{array}{c}\text { Service/ } \\
\text { Acquisition Regime }\end{array}$} & \multicolumn{2}{|c|}{ Topline Relatively Constrained } & \multicolumn{2}{|c|}{ Topline Relatively Accommodating } \\
\hline & Period (FY) & PAUC Growth & Period (FY) & PAUC Growth \\
\hline \multicolumn{5}{|l|}{ ARMY } \\
\hline DSARC & $1970-1980$ & $36 \%(13)$ & $1981-1982$ & $\mathrm{~N} / \mathrm{A}$ \\
\hline DSARC post Carlucci & $1987-1989$ & $48 \%(6)$ & $1983-1986$ & $10 \%(6)$ \\
\hline $\mathrm{DAB}$ & $1990-1993$ & $42 \%(5)$ & None & $\mathrm{N} / \mathrm{A}$ \\
\hline Acquisition Reform (AR) & $1994-2000$ & $82 \%(6)$ & None & N/A \\
\hline DAB post AR & $2001-2002$ & $62 \%(1)$ & 2003-2007 & $29 \%(2)$ \\
\hline \multicolumn{5}{|l|}{ NAVY } \\
\hline DSARC & $1970-1980$ & $25 \%(13)$ & $1981-1982$ & $-7 \%(1)$ \\
\hline DSARC post Carlucci & $1987-1989$ & $17 \%(2)$ & $1983-1986$ & $10 \%(12)$ \\
\hline $\mathrm{DAB}$ & $1990-1993$ & $31 \%(3)$ & None & N/A \\
\hline Acquisition Reform (AR) & $1994-2000$ & $55 \%(9)$ & None & $\mathrm{N} / \mathrm{A}$ \\
\hline DAB post AR & $2001-2002$ & $9 \%(1)$ & 2003-2007 & $8 \%(9)$ \\
\hline \multicolumn{5}{|l|}{ USAF } \\
\hline DSARC & $1970-1980$ & $38 \%(10)$ & $1981-1982$ & $8 \%(4)$ \\
\hline DSARC post Carlucci & 1987-1989 & $11 \%(1)$ & $1983-1986$ & $6 \%(7)$ \\
\hline DAB & 1990-1993 & $49 \%(2)$ & None & N/A \\
\hline Acquisition Reform (AR) & 1994-2000 & $77 \%(7)$ & None & $\mathrm{N} / \mathrm{A}$ \\
\hline DAB post AR & 2001-2002 & $75 \%(3)$ & 2003-2007 & $-7 \%(4)$ \\
\hline \multicolumn{5}{|l|}{ JOINT } \\
\hline DSARC & $1970-1980$ & $47 \%(6)$ & $1981-1982$ & $37 \%(1)$ \\
\hline DSARC post Carlucci & $1987-1989$ & $20 \%(2)$ & $1983-1986$ & $38 \%(4)$ \\
\hline DAB & 1990-1993 & $-7 \%(1)$ & None & $\mathrm{N} / \mathrm{A}$ \\
\hline Acquisition Reform (AR) & 1994-2000 & $50 \%(5)$ & None & N/A \\
\hline DAB post AR & 2001-2002 & $45 \%(1)$ & 2003-2007 & $8 \%(4)$ \\
\hline
\end{tabular}

Note: Numbers in parentheses are the number of observations available. 



\section{Illustrations}

\section{Tables}

Table 1. Average PAUC Growth in Successive Acquisition Regimes..............................4

Table 2. Average PAUC Growth during Different Acquisition Funding Climates.............5

Table 3. Average PAUC Growth by Acquisition Regime and Funding Climate ...............6

Table 4. Characteristics of PAUC Growth in Relatively Constrained Funding Climate...10

Table 5. Number of PAUC Growth Observations less than Zero by Acquisition Regime

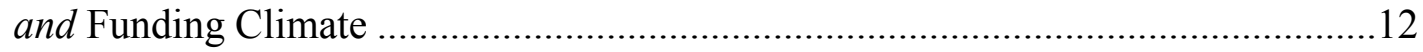

Table 6. Number of PAUC Growth Observations $\geq 50 \%$ by Acquisition Regime and Funding Climate .........................................................................................13

Table 7. Average PAUC Growth Excluding Observations $\geq 50$ Percent and Negative Observations by Acquisition Regime and Funding Climate 



\section{References}

Fox, J. Ronald. Defense Acquisition Reform, 1969 to 2009: An Elusive Goal. U.S. Army Washington, DC: Center for Military History, 2011.

Lorell, Mark A., and John C. Graser. An Overview of Acquisition Reform Cost Savings. MR-1329. Santa Monica, CA: The RAND Corporation, 2001.

McNicol, David L. Cost Growth in Major Weapon Procurement Programs, $2^{\text {nd }}$ edition. Alexandria, VA: Institute for Defense Analyses, 2004.

Tyson, Karen W., J. Richard Nelson, Neang I. Om, and Paul R. Palmer. “Acquiring Major Systems: Cost and Schedule and Acquisition Initiative Effectiveness." IDA Paper P-2201. Alexandria, VA: Institute for Defense Analyses, 1989.

Tyson, Karen W., Neang I. Om, D. Calvin Gogerty, and J. Richard Nelson, "The Effects of Management Initiatives on the Costs and Schedules of Defense Acquisition Programs, Vol. I: Main Report," IDA Paper P-2722. Alexandria, VA: Institute for Defense Analyses, 1992.

Tyson, Karen W., Neang I. Om, D. Calvin Gogerty, J. Richard Nelson, and Daniel M. Utech, "The Effects of Management Initiatives on the Costs and Schedules of Defense Acquisition Programs, Vol. II: Analysis of Ground Combat and Ship Programs," IDA Paper P-2722. Alexandria, VA: Institute for Defense Analyses, 1992.

Younossi, Obaid, Mark V. Arena, Robert S. Leonard, Charles Robert Roll, Jr., and Jerry M. Sollinger. "Is Weapon System Cost Growth Increasing? A Quantitative Assessment of Completed and Ongoing Programs.” MG588. Santa Monica, CA: The RAND Corporation, 2007. 



\section{Abbreviations}

ACAT

ANOVA

AR

CD

$\mathrm{CE}$

CLC

DAB

DAMIRS

DLC

DoD

DoDI

DSARC

EMD

FRP

FY

FYDP

IDA

JDAM

JSOW

LRIP

MAIS

MDA

MDAP

$\mathrm{MS}$

NQC

OSD

PA\&E

PAUC

PM

PPBS
Acquisition Category

Analysis of Variance

Acquisition Reform

Compact Disc

Current Estimate

Calibrated Learning Curve

Defense Acquisition Board

Defense Acquisition Management Information

Retrieval System

DAMIRS Learning Curve

Department of Defense

Department of Defense Instruction

Defense Systems Acquisition Review Council

Engineering and Manufacturing Development

Full Rate Production

Fiscal Year

Future Years Defense Plan

Institute for Defense Analyses

Joint Direct Attack Munition

Joint Standoff Weapon

Low Rate Initial Production

Major Automated Information System

Milestone Decision Authority

Major Defense Acquisition Program

Milestone

No Quantity Change

Office of the Secretary of Defense

Program Analysis and Evaluation

Program Acquisition Unit Cost

Program Manager

Planning, Programming, and Budgeting System 
RDT\&E

SAR

USAF

USD(AT\&L)

USMC

VCJCS
Research, Development, Test and Evaluation

Selected Acquisition Report

US Air Force

Under Secretary of Defense (Acquisition, Technology and Logistics)

US Marine Corps

Vice Chairman, Joint Chiefs of Staff 


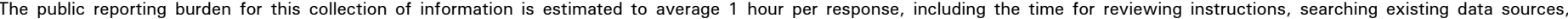

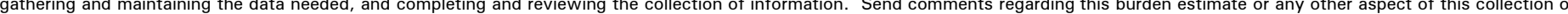

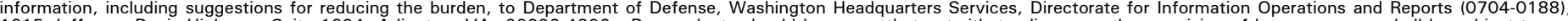

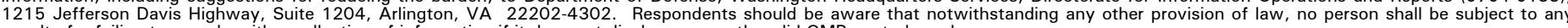
penalty for failing to comply with a collection of information if it does not display a currently valid OMB control number.

PLEASE DO NOT RETURN YOUR FORM TO THE ABOVE ADDRESS.

\begin{tabular}{|c|lc|l}
\hline $\begin{array}{c}\text { 1. REPORT DATE }(D D-M M-Y Y Y Y) \\
\text { XX-09-2014 }\end{array}$ & 2. REPORT TYPE Final & 3. DATES COVERED (From - To) \\
\hline
\end{tabular}

\section{TITLE AND SUBTITLE \\ Evidence on the Effect of DoD Acquisition Policy and Process on Cost \\ Growth of Major Defense Acquisition Programs}

5a. CONTRACT NUMBER

DASW01-04-C-0003

5b. GRANT NUMBER

5c. PROGRAM ELEMENT NUMBER

\section{6. $\operatorname{AUTHOR}(S)$}

McNicol, David, L.

$\mathrm{Wu}$, Linda

\section{5d. PROJECT NUMBER}

5e. TASK NUMBER

AY-7-357816

5f. WORK UNIT NUMBER

\section{PERFORMING ORGANIZATION NAME(S) AND ADDRESS(ES)}

Institute for Defense Analyses

4850 Mark Center Drive

Alexandria, VA 22311-1882

\section{SPONSORING/MONITORING AGENCY NAME(S) AND ADDRESS(ES)}

Director, Performance Assessments and Root Cause Analyses

Office of the Assistant Secretary of Defense for Acquisition

Room 3C889A

3620 Defense Pentagon

Washington, DC 20301-3620

\section{DISTRIBUTION/AVAILABILITY STATEMENT}

Approved for public release; distribution is unlimited.

\section{SUPPLEMENTARY NOTES}

\section{ABSTRACT}

This paper reports the results of research on whether changes in Department of Defense (DoD) acquisition policy and process have had a discernible effect on growth of Program Acquisition Unit Cost (PAUC) of major defense acquisition programs (MDAPs). Examination of PAUC growth data for 151 MDAPs that passed Milestone II or B during 1970-2007 does not reveal any substantial or consistent effect of changes in acquisition policy and process. Changes in budget climate, however, are found to have a large influence on PAUC growth. These findings have three implications for acquisition reform. First, the relevant context for understanding PAUC growth is the interface between the acquisition process and the program/budget process. Second, it seems unlikely that further changes in the acquisition process will have a major effect on PAUC growth. Third, the underlying cause of persistent high PAUC growth is not, as is commonly asserted, a deeply established culture of the DoD acquisition organizations and their professional employees. Relevant data are provided on the accompanying CD.

\section{SUBJECT TERMS}

Acquisition reform, cost growth, PAUC growth, acquisition culture, budget climate and cost growth, acquisition policy, acquisition process

\section{SECURITY CLASSIFICATION OF: \begin{tabular}{l|l|l|l|}
\hline a. REPORT & b. ABSTRACT & c. THIS PAGE
\end{tabular} Unclassified Unclassified Unclassified}

\begin{tabular}{|c|c|}
\hline $\begin{array}{c}\text { 17. LIMITATION OF } \\
\text { ABSTRACT }\end{array}$ & $\begin{array}{c}\text { 18. NUMBER } \\
\text { OF } \\
\text { PAGES } \\
\text { Same as Report }\end{array}$ \\
& 41
\end{tabular}

19a. NAME OF RESPONSIBLE PERSON Bliss, Gary, R. 19b. TELEPHONE NUMBER (Include area code)

(571) 256-0646 


